\title{
Variations in Relationships Between Perceived Stress and Birth Outcomes by Immigration Status
}

\author{
Isabelle Sinclair ${ }^{1} \cdot$ Myriane St-Pierre $^{1} \cdot$ Cathy Vaillancourt $^{2} \cdot$ Sonia Gagnon ${ }^{3} \cdot$ Kelsey N. Dancause ${ }^{1}$ (I)
}

Accepted: 23 September 2020 / Published online: 13 October 2020

(C) Springer Science+Business Media, LLC, part of Springer Nature 2020

\begin{abstract}
Introduction Past research shows that stress during pregnancy predicts adverse birth outcomes. These patterns might differ based on immigration status. Our objective was to analyze differences in relationships between perceived stress during pregnancy and birth outcomes by immigration status.

Methods We recruited 81 pregnant women in Canada for a prospective longitudinal study of stress during pregnancy and infant development. Participants completed the Perceived Stress Questionnaire at 16-18, 24-26 and 32-34 weeks of pregnancy. Birth records were available for 73 women, including 24 non-immigrants, 18 long-term immigrants ( $\geq 5$ years), and 31 recent immigrants ( $<5$ years). We used General Linear Models to test relationships between perceived stress and birthweight, birthweight for gestational age Z-scores, and gestational age, and differences based on immigration status.

Results Controlling for sociodemographic covariates, we observed interactive relationships between immigration status and perceived stress with birthweight at $16-18\left(\mathrm{p}=0.032\right.$, partial $\left.\eta^{2}=0.11\right)$ and $24-26$ weeks pregnancy $(\mathrm{p}=0.012$, partial $\left.\eta^{2}=0.15\right)$. Results were similar for birthweight for gestational age Z-scores at $16-18$ weeks $\left(p=0.016\right.$, partial $\left.\eta^{2}=0.13\right)$ and 24-26 weeks pregnancy $\left(p=0.013\right.$, partial $\left.\eta^{2}=0.14\right)$. Perceived stress predicted smaller birthweight measurements among long-term immigrants. No relation was found between perceived stress, immigration status and gestational age.

Discussion Risk of adverse health outcomes, including birth outcomes, tends to increase with duration of residence among immigrants. Stress during pregnancy might represent one risk factor for adverse birth outcomes among long-term immigrant women. Promoting psychosocial health screening and care among immigrant women, and assuring continued care with acculturation, might improve both maternal and infant health outcomes.
\end{abstract}

Keywords Stress $\cdot$ Birthweight $\cdot$ Mental health $\cdot$ Migrant $\cdot$ Immigrant $\cdot$ Health disparities

Kelsey N. Dancause

kelseydancause@gmail.com

1 Département des Sciences de l'activité physique, Faculté des sciences, Université du Québec à Montréal (UQAM), Pavillon des Sciences biologiques (SB), SB-4660, 141, avenue du Président-Kennedy, Montreal, QC H2X 1Y4, Canada

2 INRS Institut Armand-Frappier Research Centre, Montreal, QC, Canada

3 Département d'obstétrique-gynécologie, Hôpital du Sacré-Coeur de Montréal, Université de Montréal, Montreal, QC, Canada

\section{Significance}

What is already known on this subject?

Perceived stress has been associated with adverse birth outcomes such as low birthweight. Some studies show that immigrant women have higher risk for both stress and adverse birth outcomes. This risk tends to increase with time since immigration.

What this study adds?

Perceived stress might represent one risk factor underlying the increasing risk for adverse birth outcomes such as low birthweight with time since immigration observed in some studies. This emphasizes the importance of ensuring continued and long-term resources such as psychosocial health screening and care for pregnant immigrant women. 


\section{Introduction}

A record number of people globally are migrating, or living outside their country of birth (WHO 2018). In Canada, immigrants (people born outside of and living permanently in Canada) represented $21.9 \%$ of the population in 2016, and this figure is expected to increase (Statistics Canada 2005 , 2016). Patterns are similar in many high-income countries. The stresses associated with immigration might affect both physical and mental health (Alegria et al. 2017; WHO 2008, 2018). Coupled with the scale of international migration observed today, this has made migrant health a global public health priority (WHO 2008, 2018).

Pregnancy might represent a particularly stressful period among immigrant women because of sociocultural differences in prenatal care and psychosocial support (Kingston et al. 2011). Past research shows links between aspects of psychosocial health such as anxiety, depression, and stress during pregnancy, and adverse birth outcomes (Beydoun and Saftlas, 2008; Buffa et al. 2018; Dunkel Schetter and Tanner 2012; Entringer et al. 2010; Hobel et al. 2008; Kingston 2011). For example, prenatal stress predicts low birthweight and preterm birth (Bussières et al. 2015; Dunkel Schetter 2011; Glover 2015; Graignic-Philippe et al. 2014; Lima et al. 2018; Wadhwa et al. 2011), with variations based on timing of exposure because of changes in maternal responsiveness and sensitivity of developing fetal systems (Glynn et al. 2001). Patterns also differ based on sociodemographic characteristics, but few studies have analyzed differences based on immigration status.

Some studies show that psychosocial health and pregnancy outcomes are better among recent immigrant than non-immigrant women (Callister and Birkhead 2002; Kingston et al. 2011; Page 2004). However, others show more adverse psychosocial health outcomes among ethnic minority women (referring to women who do not identify with the dominant culture, in this case, white/Caucasian) (Robinson et al. 2016) and among foreign-born women (Acevedo-Garcia et al. 2005), with variations by duration of residence (Urquia et al. 2010), ethnicity (Acevedo-Garcia et al. 2005; Malin and Gissler 2009), and education (Auger et al. 2008). In general, positive patterns observed among recent immigrants become less pronounced over time (Bates and Teitler 2008; Callister and Birkhead 2002; Kingston et al. 2011; Page 2004). However, most studies of immigrant women's health during pregnancy have compared first- versus second-generation immigrants, with fewer detailed studies among first-generation immigrants (Urquia et al. 2010). Given the importance of stress during pregnancy on maternal and child health, and the stressors that immigrant women might face during pregnancy, more studies are necessary. Ultimately, these could highlight intervention routes to improve maternal and infant health for immigrant families.

Our objective was to test relationships between perceived stress during pregnancy and infant birth outcomes, and variations by immigration status, in Canada.

\section{Methods}

We conducted a prospective observational cohort study of stress during pregnancy and infant outcomes in Montreal, Canada. The sample includes a large number of first-generation immigrant women, which allows us to test differences in patterns based on immigration status and duration. This study was approved by the Research Ethics Committee of the Hôpital du Sacré-Coeur, Montréal. All participants provided written informed consent.

\section{Recruitment and Data Collection}

Participants $(\mathrm{n}=81)$ were recruited from February-December 2017 from the Hôpital du Sacré-Coeur and affiliated clinics. Recruitment was through flyers posted in waiting rooms and distributed by obstetricians. Materials were in English and French. Eligible women were in their first trimester, with singleton pregnancies. Exclusion criteria include multiple gestation, in vitro fertilization, plans to move away before delivery, cardiovascular conditions, and inability to complete questionnaires in English or French.

We collected data at 16-18, 24-26, and 32-34 weeks of pregnancy. Researchers met participants at their homes to drop off questionnaires and returned after three days to collect them. We collected data on infant characteristics from birth records.

\section{Questionnaires}

Questionnaires included maternal sociodemographic characteristics and pregnancy characteristics (number of children, due date). Participants reported their country of birth and, if relevant, number of years living in Canada. We classified immigration status based on these variables. Women born in Canada were classified as non-immigrants. Women born outside of Canada who had lived in Canada for $>5$ years were classified as long-term immigrants, and those who had lived in Canada for $<5$ years were classified as recent immigrants.

Perceived stress was assessed using the Perceived Stress Scale (Cohen et al. 1983; Lesage et al. 2012), which includes 14 questions on the degree to which life situations during the past month were appraised as stressful. Responses range from 0 ("Never") to 4 ("Very often"). Responses are summed into a total score ranging from 0 (low perceived 
stress) to 56 (high). Scores in the current sample ranged from 5 to 46 .

We included questionnaires to assess key covariates of perceived stress. We used the Multidimensional Scale of Perceived Social Support (Zimet et al. 1988) to assess support from family, friends, and significant others. Twelve questions are rated from 1 to 7 ; higher scores indicate greater social support. We used the mean score in analyses. We used the Edinburgh Postnatal Depression Scale (Cox et al. 1987) to assess depressive symptoms. Ten questions are rated from 0 to 3; higher scores indicate more depressive symptoms. We used the sum of responses and classified scores $\geq 14$ as elevated risk of depression. We used the State-Trait Anxiety Inventory (Spielberger et al. 1983) to assess symptoms of anxiety. Twenty questions are rated from 1 to 4 and summed; higher scores indicate more anxiety symptoms. Scores $\geq 40$ were classified as elevated anxiety risk.

\section{Birth Outcomes}

We collected data on infant characteristics from birth records, including sex, weight at birth in grams (birthweight), and gestational age at birth in weeks. We calculated sex- and gestational-age specific Z-scores for birthweight (birthweight for gestational age Z-scores) using Canadian references (Kramer et al. 2001). Prevalence of low birthweight $(<2500 \mathrm{~g})$ and preterm birth $(<37$ weeks) was calculated for descriptive statistics.

\section{Statistical Methods}

Analyses were conducted on the sample of 73 women with live births and birth outcome data (detailed in "Results" section). Perceived stress data were complete for 72 women at 16-18 weeks pregnancy (99\%), 70 at 24-26 weeks (96\%), and 67 at 32-34 weeks (92\%). Nine out of these ten missing data points reflected scheduling conflicts that prevented women from completing one evaluation. We imputed values for these missing data points based on perceived stress at the other two evaluation periods and sociodemographic covariates. Missing data at 32-34 weeks for one participant was due to premature delivery before the evaluation; perceived stress was not imputed for this participant.

We analyzed descriptive statistics, and differences based on immigration status, using one-way ANOVA and chi-squared analyses. For descriptive statistics (Table 1), household income and education were re-classified into three categories.

We used univariate General Linear Models to analyze relationships between perceived stress (predictor) and weight of the infant at birth (birthweight), sex- and gestational-age specific Z-scores for birthweight (birthweight Z-scores), and gestational age at birth. We first tested models including only the key variables of immigration status and perceived stress, with immigration status (non-immigrant, long-term immigrant, recent immigrant) as a fixed effect and a perceived stress*immigration status interaction term. We then re-ran models with covariates including maternal age, number of children, household income on a scale of 1-10, number of individuals in the household (household size), years of education, and visible minority status (yes or no). Visible minority, as defined by Statistics Canada, refers to persons other than Aboriginal peoples who are non-Caucasian or non-white (Statistics Canada 2020b). We also included social support (mean scores), elevated depression risk (yes or no), and elevated anxiety risk (yes or no) as covariates.

We tested models using imputed values for perceived stress for participants with missing data, and compared results to models excluding participants with missing values. Results were unchanged (data not shown), so we report models with imputed values. Analyses were conducted using SPSS version 22.0 (IBM Corp., Armonk NY).

Figure 1 illustrates significant interactive relationships between immigration status and perceived stress scores, ranging from 15 (low) to 30 (high), with birthweight for gestational age $\mathrm{Z}$-scores. Low and high values were chosen to reflect the mean of scores at the lowest and highest quartiles of perceived stress.

\section{Results}

\section{Descriptive Statistics}

Of 81 participants, 76 had a live birth. Of these, birth records were available for 73 participants (96\%), including 24 nonimmigrants (33\%), 18 long-term immigrants (25\%), and 31 recent immigrants (42\%). Among the 3 women with live births but no birth records (1 non-immigrant, 1 long-term immigrant, 1 recent immigrant), 2 abandoned the study, and 1 completed all evaluations but was then lost to contact.

Descriptive statistics are shown in Table 1. Prevalence of low birthweight was $2.7 \%$ and prevalence of preterm birth was $5.6 \%$, consistent with other Canadian studies (Government of Canada 2016; Urquia et al. 2010). Twenty countries of origin were represented among immigrant participants, including Armenia, Benin, Cameroon, Djibouti, France, Guinea, Haiti, Ivory Coast, Lebanon, Libya, Morocco, Mexico, Pakistan, Poland, Saudi Arabia, Senegal, Syria, Tunesia, Turkey, and Venezuela. Major native languages spoken included French (35\% of participants), Arabic (24\%), and Creole (8\%). A large number of participants had income $<\$ 25,000$, ranging from $37.5 \%$ among non-immigrants to $61.3 \%$ among recent immigrants. In 2017, the cutoff for "low income" as defined by Statistics Canada for a 
Table 1 Sample size, means, and standard deviations (SD) or frequencies for study variables at each evaluation period (\#1 = 16-18 weeks, \#2=24-26 weeks, \#3=32-34 weeks), with p-values testing differences based on immigration status

\begin{tabular}{|c|c|c|c|c|c|}
\hline & Non-Imm & Long-term & Recent & p-value & Full sample \\
\hline $\mathrm{N}$ & 24 & 18 & 31 & & 73 \\
\hline Age & $29.4(5.3)$ & $32.2(7.9)$ & $32.3(4.9)$ & 0.163 & $31.3(6.0)$ \\
\hline \multicolumn{6}{|l|}{ Number of children } \\
\hline 0 children, $\mathrm{n}(\%)$ & $14(58.3)$ & $11(61.1)$ & $6(19.4)$ & 0.003 & $31(42.5)$ \\
\hline 1 or more, $\mathrm{n}(\%)$ & $10(41.7)$ & $7(38.9)$ & $25(80.6)$ & & $42(57.5)$ \\
\hline Mean \# children (SD) & $0.7(1.1)$ & $0.8(1.3)$ & $1.3(0.9)$ & 0.090 & $1.0(1.1)$ \\
\hline Years in Canada & - & $15.2(7.8)$ & $2.3(1.3)$ & $<0.001$ & $7.0(7.9)$ \\
\hline \multicolumn{6}{|l|}{ Household income, n (\%) } \\
\hline$<\$ 25,000$ & $9(37.5)$ & $8(44.4)$ & $19(61.3)$ & 0.130 & $36(49.3)$ \\
\hline$\$ 25,000-\$ 50,000$ & $7(29.2)$ & $5(27.8)$ & $10(32.3)$ & & $22(30.1)$ \\
\hline$>\$ 50,000$ & $8(33.3)$ & $5(27.8)$ & $2(6.5)$ & & $15(20.5)$ \\
\hline Household size & $2.8(0.9)$ & $3.1(1.7)$ & $3.4(1.0)$ & 0.178 & $3.1(1.2)$ \\
\hline \multicolumn{6}{|l|}{ Education (\%) } \\
\hline Secondary & $12(50.0)$ & $6(33.3)$ & $5(16.1)$ & 0.008 & $23(31.5)$ \\
\hline College & $7(29.2)$ & $7(38.9)$ & $6(19.4)$ & & $20(27.4)$ \\
\hline University & $5(20.8)$ & $5(27.8)$ & $20(64.5)$ & & $30(41.1)$ \\
\hline Social Support, \#1 & $6.2(0.9)$ & $5.6(1.2)$ & $5.6(1.0)$ & 0.061 & $5.8(1.1)$ \\
\hline Social Support, \#2 & $6.2(0.9)$ & $5.5(1.6)$ & $5.6(1.0)$ & 0.059 & $5.8(1.2)$ \\
\hline Social Support, \#3* & $6.4(0.8)$ & $5.8(1.0)$ & $5.2(1.3)$ & 0.001 & $5.7(1.2)$ \\
\hline Depression, \#1, n (\%) & $2(8.3)$ & $3(16.7)$ & $5(16.1)$ & 0.646 & $10(13.7)$ \\
\hline Depression, \#2, n (\%) & $4(16.7)$ & $2(11.1)$ & $4(12.9)$ & 0.862 & $10(13.7)$ \\
\hline Depression, \#3, n (\%)* & $1(4.2)$ & $2(11.1)$ & $5(16.1)$ & 0.371 & $8(11.0)$ \\
\hline Trait Anxiety, \#1, n (\%) & $8(33.3)$ & $9(50.0)$ & $17(54.8)$ & 0.269 & $34(46.6)$ \\
\hline Trait Anxiety, \#2, n (\%) & $9(37.5)$ & $6(33.3)$ & $17(54.8)$ & 0.256 & $32(43.8)$ \\
\hline Trait Anxiety, \#3, n (\%)* & $5(20.8)$ & $5(31.3)$ & $11(40.7)$ & 0.310 & $21(31.3)$ \\
\hline Perceived Stress, \#1 & $21.9(7.5)$ & $25.1(7.6)$ & $25.3(6.8)$ & 0.192 & $24.2(7.3)$ \\
\hline Perceived Stress, \#2 & $20.8(8.1)$ & $21.8(7.7)$ & $23.8(5.6)$ & 0.290 & $22.3(7.1)$ \\
\hline Perceived Stress, \#3* & $19.7(9.5)$ & $22.1(8.0)$ & $23.1(5.7)$ & 0.270 & $21.7(7.7)$ \\
\hline Birthweight (BW) (g) & $3289(331)$ & $3329(453)$ & $3390(653)$ & 0.770 & $3342(513)$ \\
\hline Gest. age (GA) (weeks) & $39.2(1.5)$ & $39.6(0.8)$ & $39.2(2.4)$ & 0.769 & $39.3(1.8)$ \\
\hline BW for GA Z-score & $-0.17(0.75)$ & $-0.27(0.96)$ & $0.07(1.11)$ & 0.445 & $-0.10(0.97)$ \\
\hline
\end{tabular}

*One participant delivered before the evaluation period; $\mathrm{n}=72$ single person in large urban areas was $\$ 25,338$ (Statistics Canada 2020a).

\section{Relationships Between Perceived Stress and Birth Outcomes}

We first tested relationships between perceived stress and birthweight for gestational age Z-scores, with no covariates in the model. Results indicated an interaction between perceived stress and immigration status at 16-18 weeks $\left(p=0.021\right.$, partial $\left.\eta^{2}=0.11\right)$ and $24-26$ weeks pregnancy $\left(p=0.004\right.$, partial $\left.\eta^{2}=0.15\right)$. The interactive relationship was not significant at 32-34 weeks $(\mathrm{p}=0.104$, partial $\eta^{2}=0.07$ ). Results for birthweight showed the same patterns, with a significant interactive relationship between perceived stress and immigration status at $16-18$ weeks $(\mathrm{p}=0.048$, partial $\left.\eta^{2}=0.09\right)$ and $24-26$ weeks pregnancy $(p=0.012$, partial $\left.\eta^{2}=0.12\right)$ but not at $32-34$ weeks $(\mathrm{p}=0.082$, partial $\eta^{2}=0.07$ ). There were no significant interactive relationships between perceived stress and immigration status on gestational age at birth at any evaluation period (16-18 weeks, $\mathrm{p}=0.562$, partial $\eta^{2}=0.02 ; 24-26$ weeks, $\mathrm{p}=0.573$, partial $\eta^{2}=0.02 ; 32-34$ weeks, $p=0.055$, partial $\eta^{2}=0.08$ ).

Table 2 presents results of General Linear Models testing relationships between perceived stress and birthweight for gestational age Z-scores, with covariates. Results mirrored those in the original model. We observed an interaction between perceived stress and immigration status at 16-18 weeks $\left(p=0.016\right.$, partial $\left.\eta^{2}=0.13\right)$ and $24-26$ weeks pregnancy $\left(\mathrm{p}=0.013\right.$, partial $\left.\eta^{2}=0.14\right)$. At both periods, relationships between perceived stress and birthweight did not differ between non-immigrant and recent immigrant women, but differed between recent and long-term immigrant women. Figure 1 illustrates relationships between 


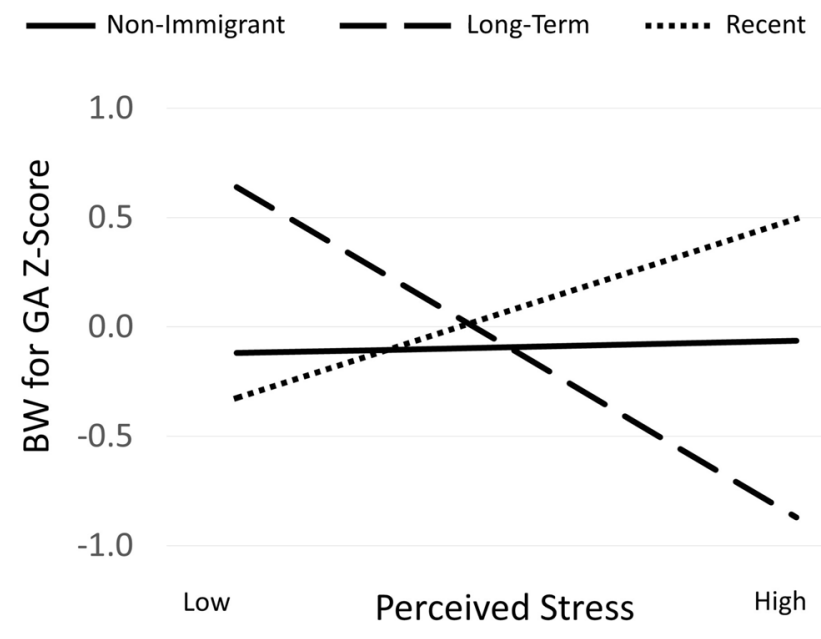

Fig. 1 Relationships between perceived stress and birthweight for gestational age Z-scores at Evaluation 2 (24-26 weeks pregnancy) by immigration status

perceived stress and birthweight for gestational age Z-scores at 24-26 weeks pregnancy. The interactive relationship was not significant at 32-34 weeks $\left(p=0.185\right.$, partial $\left.\eta^{2}=0.06\right)$. Results were similar for birthweight, with significant interactive relationships between perceived stress and immigration status at $16-18$ weeks $\left(p=0.032\right.$, partial $\left.\eta^{2}=0.11\right)$ and 24-26 weeks pregnancy $\left(p=0.012\right.$, partial $\left.\eta^{2}=0.15\right)$. The interactive relationship was not significant at 32-34 weeks $\left(\mathrm{p}=0.089\right.$, partial $\left.\eta^{2}=0.09\right)$.

Replacing number of children with parity did not change the results observed in any of the models (data not shown).

\section{Discussion}

\section{Measurement of Stress and Applications in Health Research}

Various conceptualizations of stress are applied in health research, reflecting the complexity of the stress response that encompasses emotional as well as biological and physiological reactions (Coussons-Read 2013; Schneiderman et al. 2005). We are regularly faced with situations (stressors) that require us to react or adapt. When an individual perceives a stressor as threatening or confronts a situation in which demands exceed available resources, he or she is likely to experience negative emotions or distress. These emotional reactions can be accompanied by changes in stress hormones, inflammatory cytokines, and blood circulation that, during pregnancy, might affect the developing fetus (Dunkel Schetter 2011; Glover 2014; Hobel and Culhane 2003; Lazinski et al. 2008; Wadhwa et al. 2001). Application of the concept of stress in maternal health research might address the stressor, the emotional response, and the biological or physiological response.

In the current study, we assessed pregnant women's emotional responses or perceived stress using the Perceived Stress Scale. We chose this scale because it is widely used in prenatal stress and population health research. However, this provides a perspective of only one aspect of maternal stress. The specific biological or physiological responses to perceived stress that underlie its relationships with birth outcomes are not entirely clear. Furthermore, these mechanistic pathways might differ from those underlying relationships between other constructs of mental health, such as anxiety or depression, and birth outcomes (Dunkel Schetter 2011; Dunkel Schetter and Tanner 2012). In addition, perceived stress might indirectly affect birth outcomes through relationships with health behaviors such as unhealthy diet, sedentary behavior, or tobacco use (Dunkel Schetter 2011) that are associated with stress in the general population (Ellis et al. 2015; Kiviniemi et al. 2011; Laugero et al. 2011; Ng and Jeffery 2003; St-Pierre et al. 2019; Steptoe et al. 1998; Stetson et al. 1997) and among pregnant women (Lobel et al. 2008; Rodriguez et al. 2000; Sinclair et al. 2019). This highlights the need for studies that carefully contextualize multiple aspects of the stress response as well as other maternal characteristics.

\section{Stress Among Immigrant Women}

Despite the methodological challenges in assessing stress and in pinpointing underlying pathways, the importance of stress as a key social determinant of health is well recognized (Government of Canada 2018; WHO 2003). Stress might represent one factor underlying persistent health disparities based on characteristics such as race or ethnicity, socioeconomic status, and education. Immigration might also represent a source of stress. For example, among adult Asian immigrants to the U.S., 70\% reported experiencing stress related to immigration and acculturation (Lueck and Wilson 2010). Immigrant women are already at increased risk of adverse psychosocial health outcomes than men (Ritsner et al. 2001), and pregnancy might exacerbate this risk due to challenges in accessing prenatal care, lack of familiarity with available support systems, and lack of social support (Khanlou et al. 2017; Kingston et al. 2011). For example, recent immigrants to Canada have higher risk of depression during pregnancy than Canadian-born women, with lack of social support representing a major risk factor (Kingston et al. 2011; Miszkurka et al. 2010). However, some studies show less exposure to stressful life events among pregnant immigrant compared to non-immigrant women (Kingston et al. 2011). Inconsistencies in results highlight the importance of considering duration of residence and sociodemographic characteristics in analyses. 


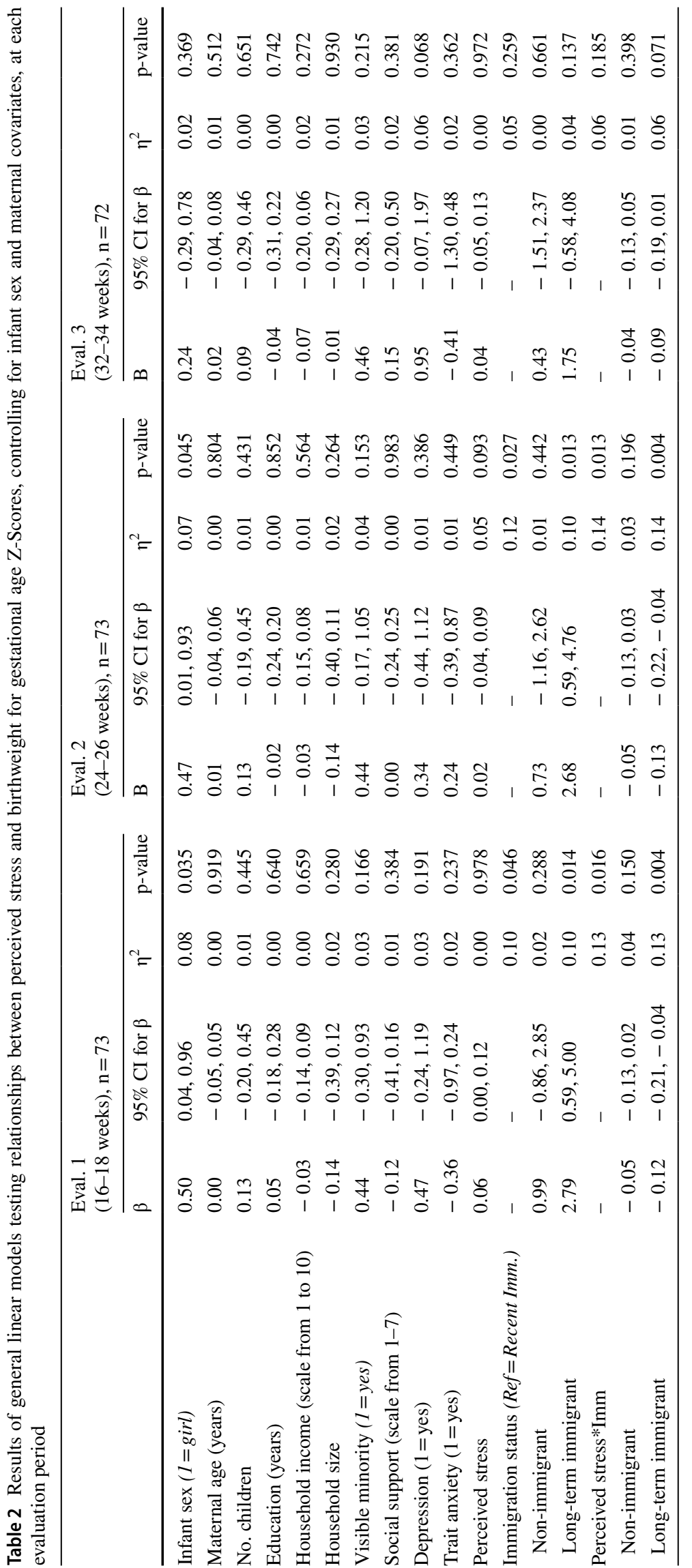




\section{Birthweight Among Immigrant Women: Potential Relationships with Prenatal Stress}

Past studies show higher risk of low birthweight among foreign-born women in the U.S. (Acevedo-Garcia et al. 2005) and Canada (Shah et al. 2011). We hypothesized that perceived stress might represent one risk factor for these patterns. Results show interactions between immigration status and perceived stress with birthweight, with greater perceived stress predicting smaller birthweights among long-term immigrant women. Relationships were significant at 16-18 and 24-26 weeks but not later in pregnancy, mirroring results from other studies suggesting that early- to mid-pregnancy is a more sensitive period for relationships between prenatal stress and birthweight (Dancause et al. 2011; Paarlberg et al. 1999; Zhu et al. 2010).

The explanation for these patterns likely reflects complex relationships between interacting biological, physiological, social, and behavioral risk factors (Khanlou et al. 2017; Viruell-Fuentes et al. 2012). Immigrant women might be more likely to gain less than the recommended amount of weight during pregnancy (Kowal et al. 2012), and less likely to use prenatal vitamins compared to non-immigrant women (Kingston et al. 2011). Furthermore, immigrant women in Canada might be less likely to follow dietary guidelines during pregnancy (Higginbottom et al. 2015), although they exhibit lower risk of other lifestyle factors such as alcohol and tobacco use (Khanlou et al. 2017). Other studies among immigrant adults show that both adverse health outcomes and risky health behaviors tend to increase with acculturation (Abraido-Lanza et al. 2005; Wolff and Portis 1996; Zambrana et al. 1997). Social and structural barriers might exacerbate these risks. Scoping reviews show, for example, that immigrant and refugee women in Canada experience barriers accessing and using prenatal care, as noted in other areas of healthcare (Khanlou et al. 2017). Similarly, whereas recent immigrants to Canada report less perceived racism compared to native-born Canadians, immigrants who have resided in Canada for 5-10 years perceive that they are treated with less respect and receive poorer service in public compared to recent immigrants or native-born Canadians (Vang and Chang 2019). We would expect different profiles of maternal stress and health outcomes across countries based on differences in immigration policies, integration profiles, and structural inequalities. However, ultimately, the patterns observed among long-term immigrants in the current study, like the decline in many other health outcomes observed with time since immigration, likely reflects intersectionality among multiple risk factors (Bowleg 2012; Khanlou et al. 2017; Viruell-Fuentes et al. 2012).

Although most studies have shown negative relationships between perceived stress and birthweight, a few indicate positive relationships between moderate stress exposure and some aspects of infant development among more advantaged samples. For example, among healthy, financially-stable women, greater maternal stress predicted enhanced motor development among children (DiPietro 2012; DiPietro et al. 2006). Indeed, cortisol is important in promoting fetal physical and neurodevelopment, but at high levels, adverse effects are observed, often varying by infant sex and timing of exposure (Hobel et al. 2008). Our results show a potential positive trend among recent immigrant women, and more studies among this subgroup are needed.

\section{Gestational Age Among Immigrant Women: Potential Relationships with Prenatal Stress}

Past studies show higher risk of small for gestational age among foreign-born women in Canada (Urquia et al. 2010) and Sweden (Li et al. 2012), compared to non-foreign-born women. Results of the current study suggest that perceived stress is not a key risk factor in these patterns. Relationships in other studies are mixed. Studies from the Danish National Birth Cohort showed that greater life stress and emotional symptoms predicted shorter gestation length, but associations were small (Tegethoff et al. 2010). Studies in Finland showed no increased risk for preterm birth among foreign-born women (Malin and Gissler 2009), and preterm birth risk was lower among immigrants and refugees to the U.S. compared to women born in the U.S. (Miller et al. 2016). Similarly, studies of preterm birth showed lower risk among immigrant compared to non-immigrant women in the U.S. and Belgium, and similar risk among immigrant and non-immigrant women in France (Guendelman et al. 1999). Patterns might vary based on length of residence: risk of preterm birth is lower among recent immigrants to Canada than non-immigrants, but higher among immigrants who had been in the country for $\geq 15$ years (Urquia et al. 2010). On the other hand, prevalence of spontaneous preterm birth was higher among immigrants in Norway, but risk was not affected by residence length (Sørbye et al. 2014). In general, if relationships between immigration status and gestational age or preterm birth are detected, they are small.

Similarly, relationships between stress during pregnancy and gestational age are mixed and often modest (Lima et al. 2018). Some have shown relationships between gestational age and stress exposure in the first trimester, but not later in pregnancy (Lederman et al. 2004). This might underlie the lack of association in the current study, as our data collection began after the first trimester, and our sample size is inadequate to detect modest relationships observed in other studies. Furthermore, it is possible that questionnaire measures of perceived stress do not capture the relevant aspect of stress that underlies relationships with gestational age. 


\section{Strengths and Limitations}

This study is limited by the small sample size, which does not permit detailed statistical analyses. Results from the convenience sample, representing one hospital in Montreal, cannot be generalized to other immigrant populations. The study is also limited by lack of detailed data on illnesses, medications, and complications during pregnancy, and data on obstetric history such as previous preterm birth and low birthweight. Pregnancy complications and obstetric history are expected not only to influence birth outcomes, but could also represent a source of stress and thereby influence perceived stress levels. We also cannot control for pre-pregnancy mental health, which might be associated with both birth outcomes and perceived stress. Further studies assessing mediating or moderating roles of maternal physical and mental health characteristics in relationships between perceived stress and birth outcomes are necessary. This study is also limited to selfreport evaluations of perceived stress, which does not provide data on the severity of stress exposure itself, or the biological or physiological responses, which might have different relationships with birth outcomes.

Cultural and linguistic differences might represent a source of bias in the measures used. Questionnaires were available in only English and French, so results cannot be generalized to women who do not speak these languages. Linguistic barriers might represent a source of stress, and we might expect that studies including women not fluent in the dominant languages of the country might show more marked results. Furthermore, $65 \%$ of our immigrant participants reported native languages other than English or French. Nuances in questions might be easier to interpret in the native language, and future studies emphasizing more linguistic diversity should be prioritized. Finally, the convenience sample is likely biased. In particular, socially disadvantaged women such as those with low education, and women with very high stress levels, might be less likely to participate. We might expect that relationships between perceived stress and birthweight would be more pronounced among these women.

Despite these possible biases, we succeeded in recruiting and retaining a diverse sample, which is a strength. Our à data collection methods, with researchers meeting women at their homes, favored participation of women who might face barriers in participating in research (Barnett et al. 2012). In addition, evaluation of perceived stress three times during pregnancy allowed us to highlight effects of timing on relationships. Finally, our study was strengthened by the prospective data collection, such that women's responses were not biased by outcomes of the pregnancy.

\section{Conclusions}

Past studies show that stress during pregnancy represents a risk factor for adverse birth outcomes, and our results show that risk might be particularly high for long-term immigrant women. This might represent one mechanism underlying the increase in risk of adverse birth outcomes with duration of residence among immigrant women observed in some studies. Further research to identify specific stressors faced by immigrant women, changes in stress exposure with acculturation, and mediating factors such as health behaviors are necessary. The American College of Obstetricians and Gynecologists recommends a psychological evaluation each trimester for all pregnant women (ACOG 2006). Taking steps to assure adequate screening and referral for long-term immigrant women might be prioritized. Although stress during pregnancy might be inevitable, programs to help pregnant women manage stress could have long-term benefits for both maternal and infant well-being.

Acknowledgements We are grateful to the families who participated in the current project, and to the Clinique Plein Ciel, the Centres intégrés de santé et de services sociaux (CISSS) de la MonteregieOuest, and the Maison des naissances Jeanne-Mance for assistance with recruitment.

\section{References}

Abraido-Lanza, A. F., Chao, M. T., \& Florez, K. R. (2005). Do healthy behaviors decline with greater acculturation?: Implications for the Latino mortality paradox. Social Science \& Medicine, 61(6), 1243-1255.

Acevedo-Garcia, D., Soobader, M. J., \& Berkman, L. F. (2005). The differential effect of foreign-born status on low birth weight by race/ethnicity and education. Pediatrics, 115(1), e20-e30. https ://doi.org/10.1542/peds.2004-1306.

Alegria, M., Alvarez, K., \& DiMarzio, K. (2017). Immigration and mental health. Current Epidemiology Reports, 4(2), 145-155. https://doi.org/10.1007/s40471-017-0111-2.

ACOG (American College of Obstetricians \& Gynecologists) Committee on Health Care for Undeserved Women. (2006). ACOG Committee Opinion No. 343: Psychosocial risk factors: Perinatal screening and intervention. Obstetrics \& Gynecology, 108(2), 469-477. https://doi.org/10.1097/00006250-200608000-00046.

Auger, N., Luo, Z. C., Platt, R. W., \& Daniel, M. (2008). Do mother's education and foreign born status interact to influence birth outcomes? Clarifying the epidemiological paradox and the healthy migrant effect. Journal of Epidemiology and Community Health, 62(5), 402-409. https://doi.org/10.1136/jech.2007.064535.

Barnett, J., Aguilar, S., Brittner, M., \& Bonuck, K. (2012). Recruiting and retaining low-income, multi-ethnic women into randomized controlled trials: Successful strategies and staffing. Contemporary Clinical Trials, 33(5), 925-932. https://doi.org/10.1016/j. cct.2012.06.005.

Bates, L. M., \& Teitler, J. O. (2008). Immigration and low birthweight in the US: The role of time and timing. Paper presented at the annual meeting of the Population Association of America. 
Beydoun, H., \& Saftlas, A. F. (2008). Physical and mental health outcomes of prenatal maternal stress in human and animal studies: A review of recent evidence. Paediatric and Perinatal Epidemiology, 22(5), 438-466. https://doi.org/10.111 1/j.1365-3016.2008.00951.x.

Bowleg, L. (2012). The problem with the phrase women and minorities: Intersectionality - an important theoretical framework for public health. American Journal of Public Health, 102(7), 1267-1273. https://doi.org/10.2105/AJPH.2012.300750.

Buffa, G., Dahan, S., Sinclair, I., St-Pierre, M., Roofigari, N., Mutran, D., et al. (2018). Prenatal stress and child development: A scoping review of research in low- and middle-income countries. PLoS One, 13(12), e0207235.

Bussières, E. L., Tarabulsy, G. M., Pearson, J., Tessier, R., Forest, J.-C., \& Giguère, Y. (2015). Maternal prenatal stress and infant birth weight and gestational age: A meta-analysis of prospective studies. Developmental Review, 36, 179-199.

Callister, L. C., \& Birkhead, A. (2002). Acculturation and perinatal outcomes in Mexican immigrant childbearing women: An integrative review. The Journal of Perinatal \& Neonatal Nursing, 16(3), 22-38.

Cohen, S., Kamarck, T., \& Mermelstein, R. (1983). A global measure of perceived stress. Journal of Health and Social Behavior, 24(4), 385-396.

Coussons-Read, M. E. (2013). Effects of prenatal stress on pregnancy and human development: Mechanisms and pathways. Obstetric Medicine, 6(2), 52-57. https://doi.org/10.1177/1753495X12 473751.

Cox, J. L., Holden, J. M., \& Sagovsky, R. (1987). Detection of postnatal depression: Development of the 10-item Edinburgh Postnatal Depression Scale. The British Journal of Psychiatry, 150(6), 782-786.

Dancause, K. N., Laplante, D., Oremus, C., Fraser, S., Brunet, A., \& King, S. (2011). Disaster-related prenatal maternal stress influences birth outcomes: Project Ice Storm. Early Human Development, 87, 813-820. https://doi.org/10.1016/j.earlhumdev 2011.06.007.

DiPietro, J. A. (2012). Maternal stress in pregnancy: Considerations for fetal development. The Journal of Adolescent Health: Official Publication of the Society for Adolescent Medicine, 51(2 Suppl), S3-S8. https://doi.org/10.1016/j.jadohealth .2012.04.008.

DiPietro, J. A., Novak, M. F., Costigan, K. A., Atella, L. D., \& Reusing, S. P. (2006). Maternal psychological distress during pregnancy in relation to child development at age two. Child Development, 77(3), 573-587. https://doi.org/10.111 $1 / \mathrm{j} .1467-8624.2006 .00891 . x$.

Dunkel Schetter, C. (2011). Psychological science on pregnancy: Stress processes, biopsychosocial models, and emerging research issues. Annual Review of Psychology, 62, 531-558. https://doi.org/10.1146/annurev.psych.031809.130727.

Dunkel Schetter, C., \& Tanner, L. (2012). Anxiety, depression and stress in pregnancy: Implications for mothers, children, research, and practice. Current Opinion in Psychiatry, 25(2), 141-148. https://doi.org/10.1097/YCO.0b013e3283503680.

Ellis, E. M., Orom, H., Giovino, G. A., \& Kiviniemi, M. T. (2015). Relations between negative affect and health behaviors by race/ethnicity: Differential effects for symptoms of depression and anxiety. Health Psychology, 34(9), 966-969. https://doi. org/10.1037/hea0000197.

Entringer, S., Buss, C., \& Wadhwa, P. D. (2010). Prenatal stress and developmental programming of human health and disease risk: Concepts and integration of empirical findings. Current opinion in Endocrinology, Diabetes, and Obesity, 17(6), 507-516. https ://doi.org/10.1097/MED.0b013e3283405921.
Glover, V. (2014). Maternal depression, anxiety and stress during pregnancy and child outcome; What needs to be done. Best Practice \& Research Clinical Obstetrics \& Gynaecology, 28(1), 25-35.

Glover, V. (2015). Prenatal stress and its effects on the fetus and the child: Possible underlying biological mechanisms. Advances in Neurobiology, 10, 269-283. https://doi. org/10.1007/978-1-4939-1372-5_13.

Glynn, L. M., Wadhwa, P. D., Dunkel-Schetter, C., Chicz-Demet, A., \& Sandman, C. A. (2001). When stress happens matters: Effects of earthquake timing on stress responsivity in pregnancy. American Journal of Obstetrics and Gynecology, 184(4), 637-642. https:// doi.org/10.1067/mob.2001.111066.

Government of Canada. (2016). Health Status of Canadians 2016: Report of the Chief Public Health Officer-How healthy are we? Low birth weight. Retrieved from https://www.canada.ca/en/publi c-health/corporate/publications/chief-public-health-officer-repor ts-state-public-health-canada/2016-health-status-canadians/page5-how-healthy-are-we-low-birth-weight.html.

Government of Canada. (2018). Social determinants of health and health inequalities. Retrieved from https://www.canada.ca/en/ public-health/services/health-promotion/population-health/whatdetermines-health.html.

Graignic-Philippe, R., Dayan, J., Chokron, S., Jacquet, A. Y., \& Tordjman, S. (2014). Effects of prenatal stress on fetal and child development: A critical literature review. Neuroscience and Biobehavioral Reviews, 43, 137-162. https://doi.org/10.1016/j.neubi orev.2014.03.022

Guendelman, S., Buekens, P., Blondel, B., Kaminski, M., Notzon, F. C., \& Masuy-Stroobant, G. (1999). Birth outcomes of immigrant women in the United States, France, and Belgium. Maternal and Child Health Journal, 3(4), 177-187.

Higginbottom, G. M., Safipour, J., Yohani, S., O’Brien, B., Mumtaz, Z., \& Paton, P. (2015). An ethnographic study of communication challenges in maternity care for immigrant women in rural Alberta. Midwifery, 31(2), 297-304. https://doi.org/10.1016/j. midw.2014.09.009.

Hobel, C., \& Culhane, J. (2003). Role of psychosocial and nutritional stress on poor pregnancy outcome. Journal of Nutrition, $133(5$ Suppl 2), 1709S-1717S. https://doi.org/10.1093/jn/133.5.1709S.

Hobel, C. J., Goldstein, A., \& Barrett, E. S. (2008). Psychosocial stress and pregnancy outcome. Clinical Obstetrics and Gynecology, 51(2), 333-348. https://doi.org/10.1097/GRF.0b013e31816f2709.

Khanlou, N., Haque, N., Skinner, A., Mantini, A., \& Kurtz Landy, C. (2017). Scoping review on maternal health among immigrant and refugee women in Canada: Prenatal, intrapartum, and postnatal care. Journal of Pregnancy, 2017, 8783294. https://doi. org/10.1155/2017/8783294.

Kingston, D. (2011). The effects of prenatal and postpartum maternal psychological distress on child development: A systematic review. Retrieved from https://www.research4children.com/data/docum ents/TheEffectsofPrenatalandPostpartumMaternalPsychologicalD istressonChildDevelopmentpdf.pdf.

Kingston, D., Heaman, M., Chalmers, B., Kaczorowski, J., O’Brien, B., Lee, L., et al. (2011). Comparison of maternity experiences of Canadian-born and recent and non-recent immigrant women: Findings from the Canadian Maternity Experiences Survey. Journal of Obstetrics and Gynaecology Canada, 33(11), 1105-1115. https://doi.org/10.1016/S1701-2163(16)35078-2.

Kiviniemi, M. T., Orom, H., \& Giovino, G. A. (2011). Race/ethnicity, psychological distress, and fruit/vegetable consumption. The nature of the distress-behavior relation differs by race/ethnicity. Appetite, 56(3), 737-740. https://doi.org/10.1016/j.appet .2011.02.012.

Kowal, C., Kuk, J., \& Tamim, H. (2012). Characteristics of weight gain in pregnancy among Canadian women. Maternal and Child 
Health Journal, 16(3), 668-676. https://doi.org/10.1007/s1099 5-011-0771-3.

Kramer, M. S., Platt, R. W., Wen, S. W., Joseph, K. S., Allen, A., Abrahamowicz, M., et al. (2001). A new and improved population-based Canadian reference for birth weight for gestational age. Pediatrics, 108(2), E35.

Laugero, K. D., Falcon, L. M., \& Tucker, K. L. (2011). Relationship between perceived stress and dietary and activity patterns in older adults participating in the Boston Puerto Rican Health Study. Appetite, 56(1), 194-204. https://doi.org/10.1016/j.appet .2010.11.001.

Lazinski, M. J., Shea, A. K., \& Steiner, M. (2008). Effects of maternal prenatal stress on offspring development: A commentary. Archives of Women's Mental Health, 11, 363-375.

Lederman, S. A., Rauh, V., Weiss, L., Stein, J. L., Hoepner, L. A., Becker, M., et al. (2004). The effects of the World Trade Center event on birth outcomes among term deliveries at three lower Manhattan hospitals. Environmental Health Perspectives, 112, $1772-1778$.

Lesage, F. X., Berjot, S., \& Deschamps, F. (2012). Psychometric properties of the French versions of the Perceived Stress Scale. International Journal of Occupational Medicine and Environmental Health, 25(2), 178-184. https://doi.org/10.2478/S1338 2-012-0024-8.

Li, X., Sundquist, K., \& Sundquist, J. (2012). Risks of small-for-gestational-age births in immigrants: A nationwide epidemiological study in Sweden. Scandinavian Journal of Public Health, 40(7), 634-640.

Lima, S. A. M., El Dib, R. P., Rodrigues, M. R. K., Ferraz, G. A. R., Molina, A. C., Neto, C. A. P., et al. (2018). Is the risk of low birth weight or preterm labor greater when maternal stress is experienced during pregnancy? A systematic review and metaanalysis of cohort studies. PLoS One, 13(7), e0200594. https:// doi.org/10.1371/journal.pone.0200594.

Lobel, M., Cannella, D. L., Graham, J. E., DeVincent, C., Schneider, J., \& Meyer, B. A. (2008). Pregnancy-specific stress, prenatal health behaviors, and birth outcomes. Health Psychology, 27(5), 604-615. https://doi.org/10.1037/a0013242.

Lueck, K., \& Wilson, M. (2010). Acculturative stress in Asian immigrants: The impact of social and linguistic factors. International Journal of Intercultural Relations, 34(1), 47-57.

Malin, M., \& Gissler, M. (2009). Maternal care and birth outcomes among ethnic minority women in Finland. BMC Public Health, 9, 84. https://doi.org/10.1186/1471-2458-9-84.

Miller, L. S., Robinson, J. A., \& Cibula, D. A. (2016). Healthy immigrant effect: preterm births among immigrants and refugees in Syracuse, NY. Maternal and Child Health Journal, 20(2), 484-493.

Miszkurka, M., Goulet, L., \& Zunzunegui, M. V. (2010). Contributions of immigration to depressive symptoms among pregnant women in Canada. Canadian Journal of Public Health, 101(5), 358-364.

Ng, D. M., \& Jeffery, R. W. (2003). Relationships between perceived stress and health behaviors in a sample of working adults. Health Psychology, 22(6), 638-642. https://doi. org/10.1037/0278-6133.22.6.638.

Paarlberg, K. M., Vingerhoets, A. J., Passchier, J., Dekker, G. A., Heinen, A. G., \& van Geijn, H. P. (1999). Psychosocial predictors of low birthweight: A prospective study. British Journal of Obstetrics and Gynaecology, 106(8), 834-841.

Page, R. L. (2004). Positive pregnancy outcomes in Mexican immigrants: What can we learn? Journal of Obstetric, Gynecologic, and Neonatal Nursing, 33(6), 783-790. https://doi.org/10.1177/08842 17504270595.

Ritsner, M., Ponizovsky, A., Nechamkin, Y., \& Modai, I. (2001). Gender differences in psychosocial risk factors for psychological distress among immigrants. Comprehensive Psychiatry, 42(2), 151-160.

Robinson, A. M., Benzies, K. M., Cairns, S. L., Fung, T., \& Tough, S. C. (2016). Who is distressed? A comparison of psychosocial stress in pregnancy across seven ethnicities. BMC Pregnancy and Childbirth, 16(1), 215. https://doi.org/10.1186/s12884-016-1015-8.

Rodriguez, A., Bohlin, G., \& Lindmark, G. (2000). Psychosocial predictors of smoking and exercise during pregnancy. Journal of Reproductive and Infant Psychology, 18(3), 203-223.

Schneiderman, N., Ironson, G., \& Siegel, S. D. (2005). Stress and health: Psychological, behavioral, and biological determinants. Annual Review of Clinical Psychology, 1, 607-628. https://doi. org/10.1146/annurev.clinpsy.1.102803.144141.

Shah, R. R., Ray, J. G., Taback, N., Meffe, F., \& Glazier, R. H. (2011). Adverse pregnancy outcomes among foreign-born Canadians. Journal of Obstetrics and Gynaecology Canada, 33(3), 207-215.

Sinclair, I., St-Pierre, M., Elgbeili, G., Bernard, P., Vaillancourt, C., Gagnon, S., et al. (2019). Psychosocial stress, sedentary behavior, and physical activity during pregnancy among Canadian women: Relationships in a diverse cohort and a nationwide sample. International Journal of Environmental Research and Public Health, 16(24), 5150. https://doi.org/10.3390/ijerph16245150.

Sørbye, I. K., Daltveit, A. K., Sundby, J., \& Vangen, S. (2014). Preterm subtypes by immigrants' length of residence in Norway: A population-based study. BMC Pregnancy and Childbirth, 14(1), 239.

Spielberger, C. D., Gorsuch, R. L., Lushene, R., Vagg, P. R., \& Jacobs, G. A. (1983). Manual for the state-trait anxiety inventory. Palo Alto, CA: Consulting Psychologists Press.

St-Pierre, M., Sinclair, I., Elgbeili, G., Bernard, P., \& Dancause, K. N. (2019). Relationships between psychological distress and health behaviors among Canadian adults: Differences based on gender, income, education, immigrant status, and ethnicity. SSM Population Health, 7, 100385. https://doi.org/10.1016/j.ssmph .2019.100385.

Statistics Canada. (2005). Les immigrants récents des régions métropolitaines: Montréal-un profil comparatif d'après le rencensement de 2001. Retrieved from https://www.canada.ca/fr/immig ration-refugies-citoyennete/organisation/rapports-statistiques/ recherche/immigrants-recents-regions-metropolitaines-montrealprofil-comparatif-apres-rencensement-2001/partiea.html.

Statistics Canada. (2016). Profil du recensement, Recensement de 2016. Retrieved from https://www12.statcan.gc.ca/census-recensemen t/2016/dp-pd/prof/details/page.cfm?Lang $=F \& G e o 1=P R \& C o d e 1$ $=24 \&$ Geo $2=$ PR $\&$ Code $2=01 \&$ Data $=$ Count $\&$ SearchText $=$ quebe $\mathrm{c} \&$ Search Type $=$ Begins $\&$ SearchPR $=01 \& \mathrm{~B} 1=\mathrm{All} \& \mathrm{TABID}=1$.

Statistics Canada. (2020a). Table 11-10-0241-01: Low income cut-offs (LICOs) before and after tax by community size and family size, in current dollars. Retrieved from https://www150.statcan.gc.ca/ $\mathrm{t} 1 / \mathrm{tb} 11 / \mathrm{en} / \mathrm{tv}$.action?pid=1110024101.

Statistics Canada. (2020b). Visible minority of person. Retrieved from https://www23.statcan.gc.ca/imdb/p3Var.pl?Funct ion $=\mathrm{DEC} \& \mathrm{Id}=45152$.

Steptoe, A., Lipsey, Z., \& Wardle, J. (1998). Stress, hassles and variations in alcohol consumption, food choice and physical exercise: A diary study. British Journal of Health Psychology, 3, 51-63.

Stetson, B. A., Rahn, J. M., Dubbert, P. M., Wilner, B. I., \& Mercury, M. G. (1997). Prospective evaluation of the effects of stress on exercise adherence in community-residing women. Health Psychology, 16(6), 515-520.

Tegethoff, M., Greene, N., Olsen, J., Meyer, A. H., \& Meinlschmidt, G. (2010). Maternal psychosocial adversity during pregnancy is associated with length of gestation and offspring size at birth: Evidence from a population-based cohort study. Psychosomatic Medicine, 72(4), 419-426. https://doi.org/10.1097/PSY.0b013 e3181d2f0b0. 
Urquia, M. L., Frank, J. W., Moineddin, R., \& Glazier, R. H. (2010). Immigrants' duration of residence and adverse birth outcomes: A population-based study. BJOG, 117(5), 591-601. https://doi.org/ 10.1111/j.1471-0528.2010.02523.x.

Vang, Z. M., \& Chang, Y. (2019). Immigrants' experiences of everyday discrimination in Canada: Unpacking the contributions of assimilation, race, and early socialization. International Migration Review, 53(2), 602-631.

Viruell-Fuentes, E. A., Miranda, P. Y., \& Abdulrahim, S. (2012). More than culture: Structural racism, intersectionality theory, and immigrant health. Social Science and Medicine, 75(12), 2099-2106. https://doi.org/10.1016/j.socscimed.2011.12.037.

Wadhwa, P. D., Culhane, J. F., Rauh, V., \& Barve, S. S. (2001). Stress and preterm birth: Neuroendocrine, immune/inflammatory, and vascular mechanisms. Maternal and Child Health Journal, 5(2), 119-125. https://doi.org/10.1023/a:1011353216619.

Wadhwa, P. D., Entringer, S., Buss, C., \& Lu, M. C. (2011). The contribution of maternal stress to preterm birth: Issues and considerations. Clinics in Perinatology, 38(3), 351-384. https://doi. org/10.1016/j.clp.2011.06.007.

WHO (World Health Organization). (2003). Social determinants of health: The solid facts. Geneva: World Health Organization.
WHO (World Health Organization). (2008). Overcoming migrants' barriers to health. Bulletin of the World Health Organization, $86(8), 583-584$.

WHO (World Health Organization). (2018). Refugee and migrant health. Retrieved from https://www.who.int/migrants/about/en/.

Wolff, C., \& Portis, M. (1996). Smoking, acculturation, and pregnancy outcome among Mexican Americans. Health Care for Women International, 17(6), 563-573.

Zambrana, R. E., Scrimshaw, S., Collins, N., \& Dunkel-Schetter, C. (1997). Prenatal health behaviors and psychosocial risk factors in pregnant women of Mexican origin: The role of acculturation. American Journal of Public Health, 87(6), 1022-1026.

Zhu, P., Tao, F., Hao, J., Sun, Y., \& Jiang, X. (2010). Prenatal life events stress: Implications for preterm birth and infant birthweight. American Journal of Obstetrics and Gynecology, 203(1), 34.e31-34.e38. https://doi.org/10.1016/j.ajog.2010.02.023.

Zimet, G. D., Dahlem, N. W., Zimet, S. G., \& Farley, G. K. (1988). The multidimensional scale of perceived social support. Journal of Personality Assessment, 52(1), 30-41.

Publisher's Note Springer Nature remains neutral with regard to jurisdictional claims in published maps and institutional affiliations. 